\title{
DENSITY FUNCTIONAL THEORY STUDY ON THE ADSORPTION OF METHANE ON KEROGEN WITH DIFFERENT FUNCTIONAL GROUPS
}

\author{
WANG, Z-H. ${ }^{1 *}-\mathrm{LI}, \mathrm{Y}^{1}{ }^{-}-\mathrm{MENG}, \mathrm{W}-\mathrm{J} .{ }^{1}-\mathrm{GUO}, \mathrm{P}{ }^{1}-\mathrm{LUO}, \mathrm{Q} .{ }^{2}-\mathrm{RAN}, \mathrm{Z}-\mathrm{L} .{ }^{3}$ \\ ${ }^{1}$ State Key Laboratory of Oil and Gas Reservoir Geology and Exploitation, Southwest \\ Petroleum University, Chengdu 610500, China \\ (phone: +86-139-8203-6861) \\ ${ }^{2}$ College of Science, Southwest Petroleum University, Chengdu 610500, China \\ ${ }^{3}$ Key Laboratory of Optical Fiber Sensing \& Communication of the Ministry of Education, \\ University of Electronics Science \& Technology of China, Chengdu 611731, China \\ *Corresponding author \\ e-mail:wangzhouhua@126.com \\ (Received $28^{\text {th }}$ Oct 2016; accepted $28^{\text {th }}$ Feb 2017)
}

\begin{abstract}
Organic matter plays a vital role in the adsorption of shale gas. The current study about adsorption capacity and adsorption law of organic matter have made abundant achievements, but the effect of functional groups on the adsorption of shale gas is still not clear. In this paper, the adsorption of $\mathrm{CH}_{4}$ on the surface of kerogen fragments with different functional groups $\left(\mathrm{OH}, \mathrm{CH}_{2} \mathrm{OH}, \mathrm{COOH}, \mathrm{CH}_{3}\right.$, $\mathrm{NH}_{2}, \mathrm{O}$ ) was studied based on first principles density functional theory (DFT). The structures, electronic properties were calculated by the generalized gradient approximation (GGA). The result shows that the existence of oxygen and nitrogen in functional groups makes kerogen has greater methane adsorption capacity. The fragment of kerogen with $\mathrm{NH}_{2}-$ has strongest methane adsorption capacity and the adsorption energy is $-5.959 \mathrm{eV}$, while the adsorption energy of the fragments of kerogen with $\mathrm{OH}$, $\mathrm{CH}_{2} \mathrm{OH}, \mathrm{COOH}, \mathrm{O}$ is between $-0.274 \mathrm{eV} \sim-0.395 \mathrm{eV}$, which is close to each other, but far less than the former; the adsorption effect is very weak for methane on the surface of kerogen fragments $\mathrm{RH} 、 \mathrm{RCH}_{3}$; Difference value of the adsorption energy is less than $0.03 \mathrm{eV}$ on the surface of same fragment of kerogen, indicating that adsorption site has little influence on methane adsorption and methane is easy to spread on the same surface.
\end{abstract}

Keywords: first principles, fragments, adsorption energy, electronic state density, shale gas

\section{Introduction}

Shale gas is an important unconventional natural gas resource, widely distributed in the world. The success of the development of shale gas in North America, stimulates and promotes the exploitation of the shale gas worldwide. From the perspective of geochemistry, organic rich shale is a kind of granular material, which is composed of organic-phase kerogen that dispersed in the nonorganic matrix (such as quartz, clay minerals, etc.) (Collell et al., 2014). Because of the existence of organic phase, the connectivity of the pore networks is very poor, and about the $50 \%$ of shale gas is adsorbed on organic-phase kerogen in shale gas reservoir (such as Barnett Shale) (Wang et al., 2009). The main components of shale gas are alkanes. In addition to a small number of ethane, propane and butane, the number of methane accounted for the vast majority (Zou et al., 2011). Therefore, the study on the adsorption of methane in organic-phase kerogen is the main direction in shale gas research area. 
At present, the research on the adsorption of methane in organic matter has two sides, experimental study and theoretical study. In the experimental study, the researchers mainly used the physical and chemical method to separate the sample from the shale, and used the method of volume or weight to test the adsorption capacity of methane (Hu, 2014; Zhang et al., 2012). However, in the aspect of theoretical research, the adsorption of methane in carbon nanopores, such as kerogen, carbon nanotubes and graphene, were studied by Monte Carlo method (Collell et al., 2014; Bartuś and Bródka, 2011; Billemont et al., 2010; Billemont et al., 2013). Previous research was mainly on the description and analysis for adsorption isotherm which could reflect the adsorption capacity of kerogens for methane, and has already obtained many achievements. But few scholars have applied the density functional theory (DFT) to study the effect of functional groups of organic matter on the adsorption of methane.

The application of first principles calculation for the adsorption of gas molecules on the surface of materials has been reported. Leenaerts et al. (Leenaerts et al., 2008; Leenaerts et al., 2009) researched the adsorption of $\mathrm{H}_{2} \mathrm{O}, \mathrm{NH}_{3}, \mathrm{NO}_{2}$ and some else gas molecules on the surface of graphene by using the DFT. Based on applying the ideal grapheme surface to construct the structure of the coal seam, Y. Liu et al. (Liu and Wilcox, 2009) analyzed the adsorption law of $\mathrm{CO}_{2}$ in different scale space with the DFT. However, the results of these studies can hardly be applied to explain the adsorption of shale gas on organic matter surface. In this paper, it calculates the adsorption structure and properties of methane on the surface of kerogen fragments with different functional groups (Behar and Vandenbroucke, 1987) $\left(\mathrm{OH}, \mathrm{CH}_{2} \mathrm{OH}, \mathrm{COOH}\right.$, $\mathrm{CH}_{3}, \mathrm{NH}_{2}, \mathrm{O}$ ) by using the first principle method, compares the adsorption of $\mathrm{CH}_{4}$ on different sites on the same kerogen fragment surface, and analyzes the structure, adsorption energy and electronic properties of the kerogen fragment after the adsorption of $\mathrm{CH}_{4}$. Thus, the quantum mechanical mechanism of the interaction between $\mathrm{CH}_{4}$ and organic matter is understood, which provides a certain theoretical support to the development of shale gas reservoir.

\section{Methods and models}

Based on the density functional theory (Hohenberg and Kohn, 1964; Kohn and Sham, 1965), the first principle method was used to calculate the ground state geometries and electronic properties of methane adsorbed on the surface of kerogen fragments with different functional groups. Calculation was implemented in the CASTEP, a program that was developed by the condensed state physics research group of University of Cambridge. The reliability of the program had been verified by a large number of practical calculations. The structure of the kerogen is a kind of aromatic structure, which is composed by functional groups and a kind of aromatic unit with cross-linked alkyl chains. In order to study the effect of different functional groups on the adsorption of $\mathrm{CH}_{4}$ in kerogen, we referred to the method of constructing the structure of kerogen by Yiannourakou et al. in this work (Yiannourakou et al., 2013). Functional group was connected to the symmetrical site of polycyclic aromatic structures to construct a fragment of kerogen, which was used to simulate the surface of organic matter. When the aromatic structure $(\mathrm{R})$ is connected with hydrogen atom, it is called the kerogen fragment RH. Similarly, when R is connected with $\mathrm{OH}$, it is called the kerogen fragment $\mathrm{ROH}$, and the rest is the same as the law. The structures of kerogen fragments after optimization are shown in Fig. 1. 
The calculation of the CASTEP program which requires the system to have the periodicity is based on the total energy pseudopotential method and the plane wave expansion (Blöchl, 1994; Kresse and Joubert, 1999). When calculated, it was the first to optimize the structure of different kerogen fragments. In order to simulate the adsorption of $\mathrm{CH}_{4}$ on the surface of organic matter, the hydrogen atoms in the aromatic structure were fixed, while the position of carbon atoms in aromatic structure, functional groups and the adsorbed $\mathrm{CH}_{4}$ were variable in structure optimization calculation. On the optimization of the surface structure, the vacuum region was left on the surface of the kerogen with thickness of $1.7 \mathrm{~nm}$, to avoid the interference between the layers.

The single kerogen fragment was treated as a single cell. In this work, the $p(1 \times 1)$ cell was used. It optimized the structure of cell before the calculation of adsorbing $\mathrm{CH}_{4}$ in different high symmetry sites (the bridge, the top and the hole). The results showed that wherever the site of hydrogen atom in $\mathrm{CH}_{4}$ changed on the surface of the kerogen, the effect on the adsorption for $\mathrm{CH}_{4}$ was little. So the change of the site of hydrogen atom was not considered. To make the result better convergence in the process of optimizing structure, the BFGS optimization algorithm proposed by Broyden et al. (Broyden, 1970; Fletcher, 1970; Goldfarb, 1970; Shanno, 1970) was used for geometry optimization. Exchange-correlation energy was obtained by using generalized gradient approximation (GGA-PBE), which was proposed by Perdew et al. (Perdew et al., 1996). Using a $240.0 \mathrm{eV}$ plane wave set the cutoff. The value of self-consistent field (SCF) tolerance was $1.0 \times 10^{-5} \mathrm{eV} .1 \times 1 \times 1 \mathrm{k}$ point sampling was used (Monkhorst and Pack, 1976). The value of maximum force tolerance was $0.1 \mathrm{eV} / \mathrm{nm}$.

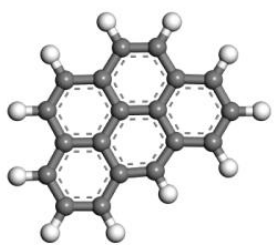

(a) RH

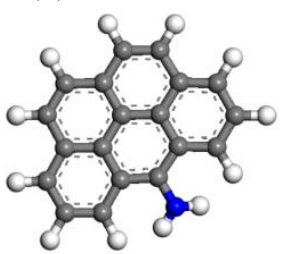

(e) $\mathrm{RNH}_{2}$

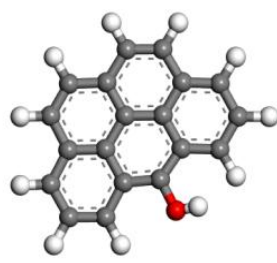

(b) $\mathrm{ROH}$

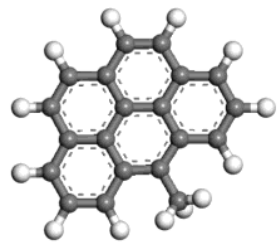

(c) $\mathrm{RCH}_{3}$

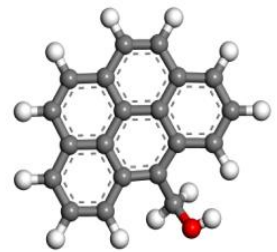

(d) $\mathrm{RCH}_{2} \mathrm{OH}$

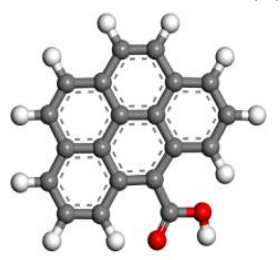

(f) $\mathrm{RCOOH}$

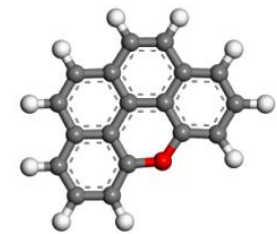

(g) $\mathrm{RO}$

Figure 1. Kerogen fragments after optimization (Atoms representation: gray is for carbon atoms, white for hydrogen, red for oxygen, and blue for nitrogen).

\section{Results and discussion}

Herein, the adsorption of methane on the surface of different organic-phase kerogen fragments was studied. As shown in Fig. 2, the high symmetry sites on the surface of the kerogen fragment include the top site $(\mathrm{T})$, the bridge site $(\mathrm{B})$ and the hole site $(\mathrm{H})$. The position of $\mathrm{T}$ site is over the atom which connected with aromatic structure in functional group. 

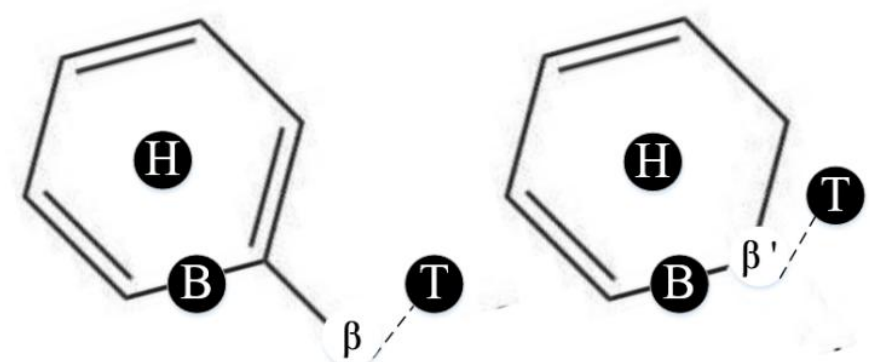

Figure 2. High-symmetry adsorption sites on the surface of Kerogen fragments ( $\beta$ represents $H$, $\mathrm{OH}, \mathrm{CH}_{2} \mathrm{OH}, \mathrm{COOH}, \mathrm{CH}_{3}, \mathrm{NH}_{2} ; \beta$ ' represents $\mathrm{O}$ ).

In Fig. 3 the cases of methane molecules adsorbed on the surface of $\mathrm{RNH}_{2}$ (B), (T) and $(\mathrm{H})$ are showed as structure (a), (b) and (c), respectively. The pink atoms in picture (a) represent the fixed atoms, and the dark gray atoms the non-fixed.

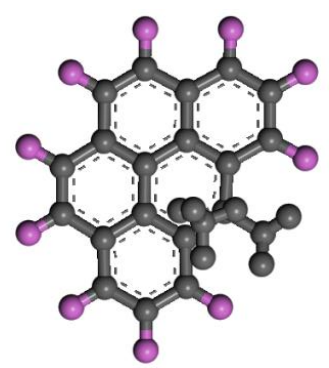

(a)

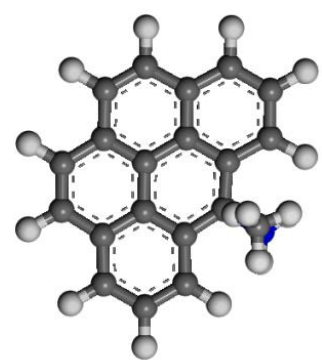

(b)

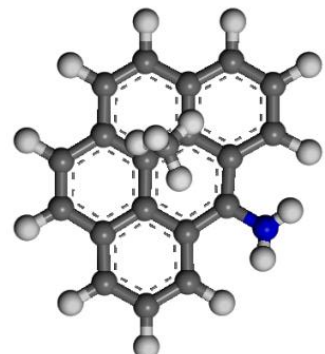

(c)

Figure 3. Structure of Kerogen fragments with $\mathrm{NH}_{2}$ after adsorbing methane on different adsorption sites.

In order to analyze the stability of methane molecules adsorbed on different positions of the kerogen fragment, the adsorption energy of methane molecules at each position was calculated. Adsorption energies $\left(E_{a d}\right)$ are calculated from

$$
E_{a d}=E_{\mathrm{CH}_{4} / \text { Kero }}-\left(E_{\text {Kero }}+E_{\mathrm{CH}_{4}}\right)
$$

where $E_{C H 4 / K e r o}, E_{K e r o}$ and $E_{C H 4}$ are energies of the adsorption system, the isolated kerogen molecule, the isolated methane molecule, respectively. The formula shows that the adsorption energy is negative, and the process of adsorption is exothermic. The smaller the value is, the easier the adsorption process occurs.

Adsorption energy and location of methane on the surface of different kerogen fragments are showed in (Table 1). By comparison, it is found that the distance $\left(d_{0}\right)$ between the carbon atoms in methane and the plane of the kerogen fragment is changed. In the $\mathrm{H}$ site of kerogen fragment $\mathrm{ROH}$ and $\mathrm{RO}, d_{0}$ is less than $0.4 \mathrm{~nm}$. In the $\mathrm{B}, \mathrm{T}$ sites, $d_{0}$ is between $0.4 \sim 0.45 \mathrm{~nm}$, and in the rest position of kerogen fragment, $d_{0}$ is between $0.5 \sim 0.6 \mathrm{~nm}$. So the correlation between the size of $d_{0}$ and the adsorption energy $E_{a d}$ is not strong. 
Table 1. Adsorption energy and location of methane on the surface of different segments of kerogen.

\begin{tabular}{c|c|c|c|c|c|c}
\hline \multirow{2}{*}{ Kerogen fragment } & \multicolumn{2}{|c|}{ T (top) } & \multicolumn{2}{c|}{ B (bridge) } & \multicolumn{2}{c}{ H (hole) } \\
\cline { 2 - 7 } & $\boldsymbol{E}_{\boldsymbol{a d}} / \boldsymbol{e v}$ & $\boldsymbol{d}_{\boldsymbol{0}} / \boldsymbol{n} \boldsymbol{m}$ & $\boldsymbol{E}_{\boldsymbol{a d}} / \boldsymbol{e v}$ & $\boldsymbol{d}_{\boldsymbol{d}} / \boldsymbol{n m}$ & $\boldsymbol{E}_{\text {add }} / \boldsymbol{e v}$ & $\boldsymbol{d}_{\boldsymbol{0}} / \boldsymbol{n m}$ \\
\hline $\mathrm{RH}$ & 0.051 & 0.504 & 0.037 & 0.574 & 0.058 & 0.504 \\
$\mathrm{ROH}$ & -0.351 & 0.415 & -0.373 & 0.439 & -0.363 & 0.387 \\
$\mathrm{RCH}_{3}$ & 0.046 & 0.592 & 0.036 & 0.557 & 0.05 & 0.504 \\
$\mathrm{RCH}_{2} \mathrm{OH}$ & -0.376 & 0.507 & -0.396 & 0.503 & -0.395 & 0.502 \\
$\mathrm{RCOOH}$ & -0.377 & 0.501 & -0.395 & 0.505 & -0.393 & 0.523 \\
$\mathrm{RO}$ & -0.274 & 0.446 & -0.25 & 0.445 & -0.254 & 0.363 \\
$\mathrm{RNH}_{2}$ & -5.959 & 0.522 & -5.939 & 0.58 & -5.946 & 0.505 \\
\hline
\end{tabular}

Adsorption energies of the most stable adsorption site of methane after adsorbed on different kerogen fragments are showed in (Fig. 4). When the methane is adsorbed on the $\mathrm{T}$ site of kerogen fragment $\mathrm{RNH}_{2}$, the adsorption energy for a minimum of $-5.959 \mathrm{eV}$ is far less than that of other types of kerogen fragments, which indicating the adsorption on kerogen fragment $\mathrm{RNH}_{2}$ is the strongest. The methane on the $\mathrm{B}$ site of $\mathrm{ROH}$, $\mathrm{RCH}_{2} \mathrm{OH}, \mathrm{RCOOH}$ has the most stable adsorption. The adsorption energies are $0.373 \mathrm{eV},-0.396 \mathrm{eV},-0.395 \mathrm{~V}$, respectively. The difference is very small, and it illustrates that their adsorption capacity for methane is close. While the most stable adsorption site on kerogen fragment $\mathrm{RO}$ is the $\mathrm{T}$ site, and the adsorption energy is $-0.274 \mathrm{eV}$, showing that the adsorption capacity of methane is slightly weaker than that of the above three kinds of kerogen. On the T, B, H sites of kerogen fragment $\mathrm{RH}$ and $\mathrm{RCH}_{3}$, the adsorption energies are both close to zero, explaining the adsorption capacity for methane of two kerogens are very weak. By comparing the elements of the functional groups, it is not difficult to find that the presence of oxygen and nitrogen element makes the adsorption of kerogens more powerful.

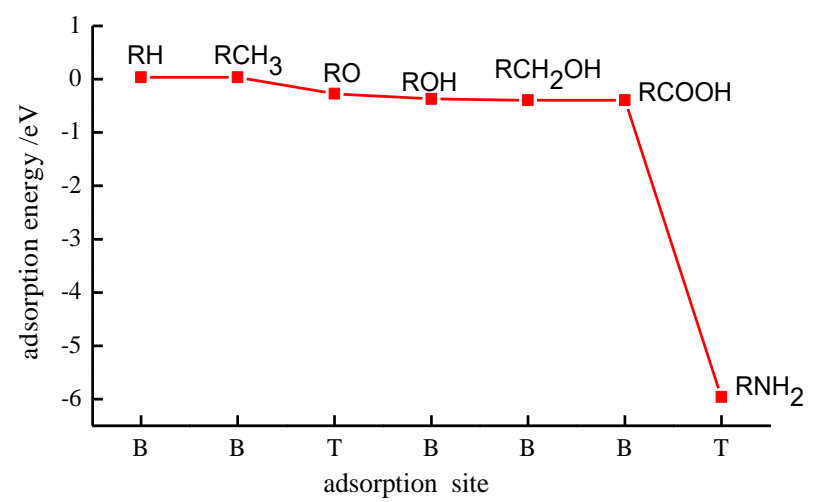

Figure 4. Adsorption energy of the most stable adsorption site of kerogen fragments.

Fig. 5 shows both the density of states of $\mathrm{CH}_{4}$ before and after it is adsorbed on the surface of kerogen fragment $\mathrm{RNH}_{2}$. Before the adsorption, three isolated peaks appear nearby the energy of $-7.5 \mathrm{eV}, 0,9 \mathrm{eV}$ in black curve. However, the distribution of three peaks significantly moves to the lower energy region once the adsorption occurs. At the 
same time, the value of peaks is lower than that of the former too. It indicates that $\mathrm{CH}_{4}$ molecule has been adsorbed on the surface of the kerogen fragment with the energy reduced. But after the adsorption in the different site on kerogen surface, the change of the density of states distribution of $\mathrm{CH}_{4}$ is not obvious. Combined with Table 1, it can be seen that the difference of adsorption energy is very small when $\mathrm{CH}_{4}$ adsorbed on the three high symmetry sites in the same kerogen, and the maximum is no more than $0.03 \mathrm{eV}$. This means that $\mathrm{CH}_{4}$ is easy to diffuse on the surface of the same kerogen. In Fig. 3(c), $\mathrm{CH}_{4}$ appears in the $\mathrm{B}$ site after adsorbed on $\mathrm{H}$ site. So it is proved that the diffusion phenomenon of $\mathrm{CH}_{4}$ does exist.

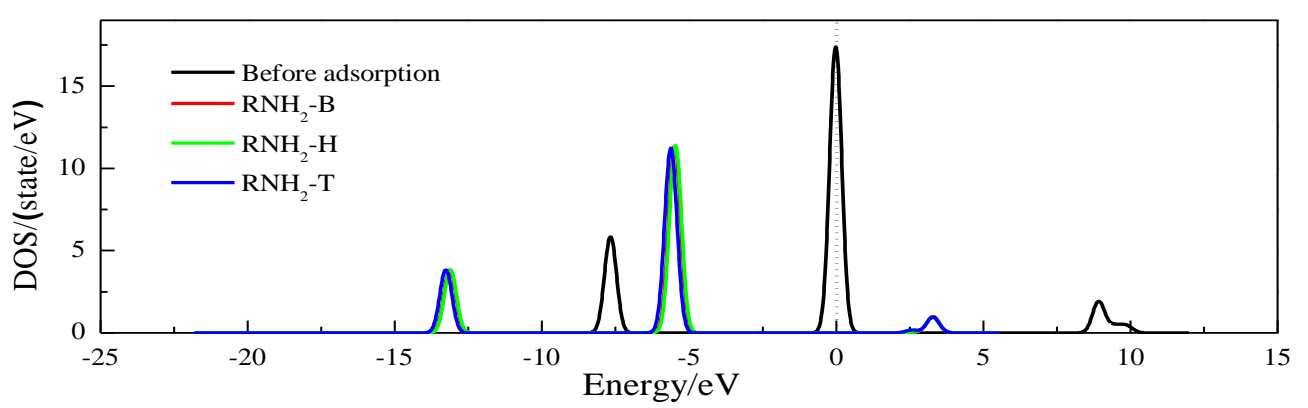

Figure 5. Density of states of methane before and after it adsorbing on the surface of kerogen fragment $\mathrm{RNH}_{2}$.

Fig. 6 shows the density of states of $\mathrm{CH}_{4}$ after it is adsorbed on the $\mathrm{B}$ site of kerogen fragments $\mathrm{RH}, \mathrm{RCH}_{3}, \mathrm{ROH}$ and $\mathrm{RNH}_{2}$. Compared to the density of states before adsorbed, the distribution of the density of states obviously moves to the lower energy region when the adsorption occurs on the surface of different kerogens. However, the distribution regions of the density of states of $\mathrm{CH}_{4}$ are almost coincident.

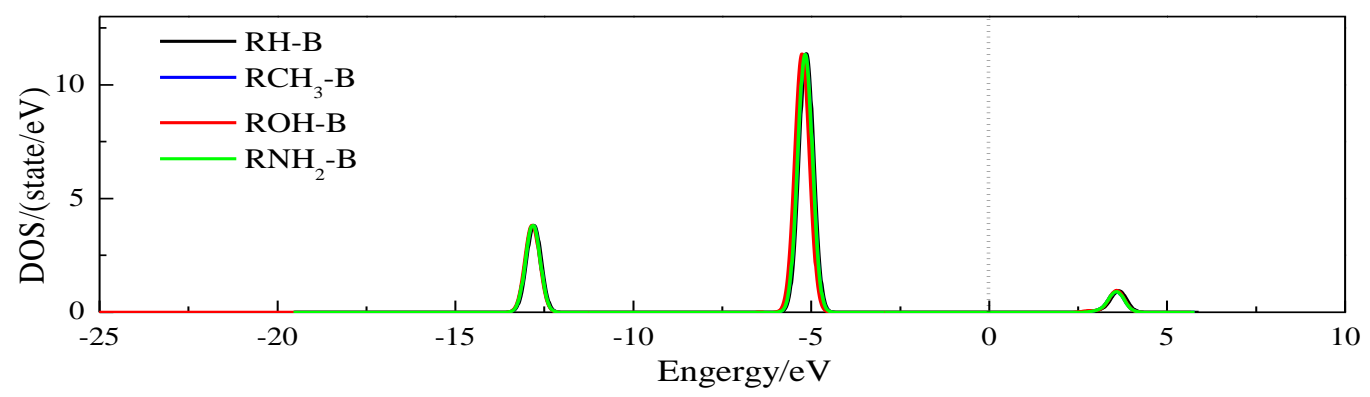

Figure 6. Density of states of methane after it adsorbing on B site of different kerogen fragments.

In order to further analyze the influence of different functional groups on the adsorption of methane, we compared the density of states of aromatic structure (R) after the adsorption of methane in the $\mathrm{B}$ site of kerogen fragments $\mathrm{RCH}_{3}, \mathrm{ROH}, \mathrm{RNH}_{2}$ and RH. In Fig. 7(a), the density of states of aromatic structure $\mathrm{R}$ in $\mathrm{RCH}_{3}$ and $\mathrm{RH}$ are both continuously distributed in the region of the energy $-18.5 \mathrm{eV} \sim 5 \mathrm{eV}$, and the two curves are close to coincidence, which indicates that the functional groups $\mathrm{CH}_{3}$ have little effect on the adsorption of methane to the kerogen. In Fig. 7(b), the energy distribution 
regions of the density of states with different $\mathrm{R}$ are arranged in order of $\mathrm{RNH}_{2}$ (the green curve), $\mathrm{ROH}$ (the red curve), $\mathrm{RH}$ (the black curve) from low to high. This shows that the energy of aromatic structure of $\mathrm{RNH}_{2}$ becomes smaller and the structure becomes more stable after adsorption. From another point of view, it also explains that the presence of oxygen and nitrogen in functional groups enhances the adsorption capacity of $\mathrm{RNH}_{2}$ and $\mathrm{ROH}$, and the adsorption capacity of the functional group $\mathrm{RNH}_{2}$ is more than that of functional groups $\mathrm{OH}$.
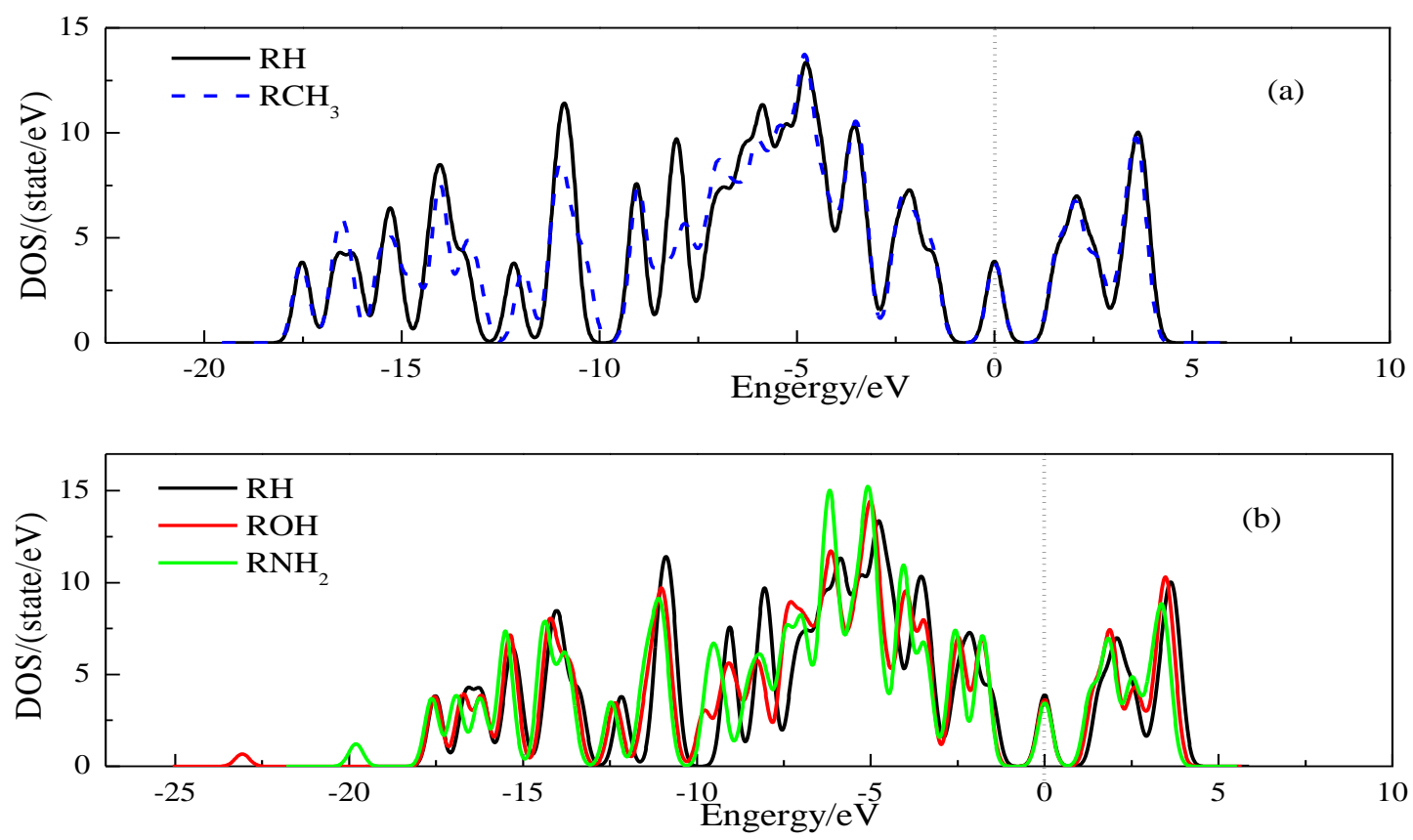

Figure 7. Density of states of the aromatic structure after methane adsorbing on B site of different kerogen fragments.

\section{Conclusions}

In this article, the problem that the adsorption of $\mathrm{CH}_{4}$ on the surface of fragments $\mathrm{RH}, \mathrm{ROH}, \mathrm{RCH}_{3}, \mathrm{RCH}_{2} \mathrm{OH}, \mathrm{RCOOH}, \mathrm{RNH}_{2}$ and $\mathrm{RO}$ of kerogen was studied in firstprinciple theory based on the density functional theory. The structure, electronic state density and adsorption energy properties while $\mathrm{CH}_{4}$ is adsorbed on the surface of kerogen are obtained. Meanwhile, the sorption behavior of $\mathrm{CH}_{4}$ on the surface of different fragments of kerogen was analyzed. Conclusions are as follows.

(1) In kerogen, the existence of the functional group that contains oxygen and nitrogen element will strengthen its ability of adsorbing $\mathrm{CH}_{4}$.

(2) The adsorption ability of fragment $\mathrm{RNH}_{2}$ is the strongest for the adsorption of $\mathrm{CH}_{4}$, while the adsorption ability of other fragments $\mathrm{ROH}, \mathrm{RCH}_{2} \mathrm{OH}, \mathrm{RCOOH}$ and $\mathrm{RO}$ are nearly the same and far less than that of the former.

(3) The adsorption energy of kerogen fragments $\mathrm{RH}$ and $\mathrm{RCH}_{3}$ are both close to zero on the $\mathrm{T}$ site, $\mathrm{B}$ site and $\mathrm{H}$ site. The adsorptive action to $\mathrm{CH}_{4}$ is very weak.

(4) The difference value of adsorption energy of $\mathrm{CH}_{4}$ on the $\mathrm{T}$ site, $\mathrm{B}$ site and $\mathrm{H}$ site in the same fragment of kerogen is less than $0.03 \mathrm{eV}$. It indicates that the effect of adsorption site on the adsorption of $\mathrm{CH}_{4}$ is small and the diffusion of $\mathrm{CH}_{4}$ on the surface of the same kerogen fragment is easy to happen. 
Although the ability of functional group $\mathrm{RNH}_{2}$ to adsorb $\mathrm{CH}_{4}$ is the strongest, its effect on the ability of kerogen to adsorb $\mathrm{CH}_{4}$ is limited as the content of nitrogen in kerogen is quite few. However, oxygen is the important constituent element of kerogen (Vandenbroucke and Largeau, 2007). Therefore, the content of oxygen in kerogen can significantly influence its ability to absorb $\mathrm{CH}_{4}$. In other words, the bigger the atomic ratio of $\mathrm{O} / \mathrm{C}$ is, the stronger the adsorption ability of kerogen should be. In experimental test, the ability of different types of kerogen to adsorb $\mathrm{CH}_{4}$ is (Zhang et al., 2012): Type I kerogen < Type II kerogen < Type III kerogen, and the corresponding $\mathrm{O} / \mathrm{C}$ atomic ratios are 0 0.1, 0.1 0.2 and 0.2 0.3 respectively (Tissot et al., 1974). The results of experiment are consistent with the conclusions obtained in this article and the conclusions can also explain the results in micro-scale. Therefore, the $\mathrm{O} / \mathrm{C}$ atomic ratio as an important indicator to evaluate the adsorption capacity of kerogen can be further studied in the future.

Acknowledgements. We are very grateful to the National Natural Science Fund Project (51204141), Exploration and Development Collaborative Innovation Center of Shale Gas in Sichuan (2013010) and the National Scholarship Council Special Training Project Fund in the Western Region (201508515157).

\section{REFERENCES}

[1] Bartuś, K., Bródka, A. (2011): Methane in carbon nanotube: molecular dynamics simulation. - Molecular Physics 109: 1691-1699.

[2] Behar, F., Vandenbroucke, M. (1987) Chemical modelling of kerogens. - Organic Geochemistry 11: 15-24.

[3] Billemont, P., Coasne, B., De, W.G. (2010): An experimental and molecular simulation study of the adsorption of carbon dioxide and methane in nanoporous carbons in the presence of water. - Langmuir 27: 1015-1024.

[4] Billemont, P., Coasne, B., De, W.G. (2013): Adsorption of carbon dioxide, methane, and their mixtures in porous carbons: effect of surface chemistry, water content, and pore disorder. - Langmuir 29: 3328-3338.

[5] Blöchl, P.E. (1994): Projector augmented-wave method. - Physical Review B 50:1795317979.

[6] Broyden, C.G. (1970): The convergence of a class of double-rank minimization algorithms 1. general considerations. - IMA Journal of Applied Mathematics 6: 76-90.

[7] Collell, J., Galliero, G., Gouth, F., Montel, F., Pujol, M., Ungerer, P., Yiannourakou, M. (2014): Molecular simulation and modelisation of methane/ethane mixtures adsorption onto a microporous molecular model of kerogen under typical reservoir conditions. Microporous and Mesoporous Materials 197: 194-203.

[8] Fletcher, R. (1970): A new approach to variable metric algorithms. - The computer journal 13: 317-322.

[9] Goldfarb, D. (1970): A family of variable-metric methods derived by variational means. Mathematics of computation 24: 23-26.

[10] Hohenberg, P., Kohn, W. (1964): Inhomogeneous electron gas. - Physical Review 136: B864-B871.

[11] Hu, H. (2014): Methane adsorption comparison of different thermal maturity kerogens in shale gas system. - Chinese Journal of Geochemistry 33: 425-430.

[12] Kohn, W., Sham, L.J. (1965): Self-Consistent Equations Including Exchange and Correlation Effects. - Physical Review 140: 1133-1138.

[13] Kresse, G., Joubert, D. (1999): From ultrasoft pseudopotentials to the projector 
augmented-wave method. - Physical Review B 59: 1758-1775.

[14] Leenaerts, O., Partoens, B., Peeters, F.M. (2008): Adsorption of $\mathrm{H}_{2} \mathrm{O}, \mathrm{NH}_{3}, \mathrm{CO}, \mathrm{NO}_{2}$, and NO on graphene: A first-principles study. - Physical Review B 77.

[15] Leenaerts, O., Partoens, B., Peeters, F.M. (2009): Adsorption of small molecules on graphene. - Microelectronics Journal 4: 860-862.

[16] Liu, Y., Wilcox, J. (2009): $\mathrm{CO}_{2}$ adsorption on carbon models of organic constituents of gas shale and coal. - Environmental science \& technology 45: 809-814.

[17] Monkhorst, H.J., Pack, J.D. (1976): Special points for Brillouin-zone integrations. Physical Review B 13:5188-5192.

[18] Perdew, J.P., Burke, K., Ernzerhof, M. (1996): Generalized gradient approximation made simple. - Physical review letters 18: 3865-3868.

[19] Shanno, D.F. (1970): Conditioning of quasi-Newton methods for function minimization. - Mathematics of computation 24: 647-656.

[20] Tissot, B., Durand, B., Espitalie, J., Combaz, A. (1974): Influence of nature and diagenesis of organic matter in formation of petroleum. - AAPG Bulletin 58: 499-506.

[21] Vandenbroucke, M., Largeau, C. (2007): Kerogen origin, evolution and structure. Organic Geochemistry 38: 719-833.

[22] Wang, F.P., Reed, R.M., Jackson, J.A. (2009): Pore Networks and Fluid Flow in Gas Shales. - SPE Journal 10: 4-7.

[23] Yiannourakou, M., Ungerer, P., Leblanc, B., Rozanska, X., Saxe, P., Vidal-Gilbert, S. (2013): Molecular simulation of adsorption in microporous materials. - Oil \& Gas Science \& Technology 68:146-158.

[24] Zhang, T., Ellis, G.S., Ruppel, S.C., Milliken, K., Yang R. (2012): Effect of organicmatter type and thermal maturity on methane adsorption in shale-gas systems. - Organic Geochemistry 47: 120-131.

[25] Zou, C.N., Dong, D.Z., Yang, H., Wang, Y.M., Huang, J.L., Wang, S.F., Fu, C.X. (2011): China shale gas formation conditions and exploration practice. - Natural Gas Industry 31: 26-39. 